\title{
Effect of Kawasaki Disease on Migration of Human Umbilical Vein Endothelial Cells
}

\author{
KOICHI SAKATA, MASAKAZU KITA, JIRO IMANISHI, ZENSHIRO ONOUCHI, YALI LIU, AND \\ YOUJI MITSUI \\ Division of Pediatrics, Children's Research Hospital [K.S., Z.O., Y.L.], Kyoto Prefectural University of \\ Medicine and Department of Microbiology [M.K., J.I.], and National Institute of Bioscience and \\ Human-Technology [Y.M.], Kamigyo-ku, Kyoto 602, Japan
}

\begin{abstract}
Wawasaki disease, which is characterized by systemic vasculitis causing coronary arterial involvement in childhood, shows a variety of immunoregulatory abnormalities. Especially the direct or indirect deleterious effects on endothelial cells of cytokines and anti-endothelial cell antibodies (AECA) are considered to be involved in the mechanism responsible for production of vasculitis. Intravenous administration of high doses of $\gamma$-globulin (IVGG) has been used as an effective therapy for Kawasaki disease. To examine the behavior of endothelial cells affected by cytokines and IVGG in Kawasaki disease, we studied the effects of interferon (IFN), IL-1 $\beta$, IL-6, and tumor necrosis factor (TNF) $\alpha$ on the migration of human umbilical vein endothelial cell line (tHUE01) by a modified Boyden chamber method. Plasma from patients with acute Kawasaki disease markedly enhanced the migration of tHUE01 cells. Cytokines, with the exception of TNF- $\alpha$, also enhanced the migration of tHUE01 cells in a dose-dependent manner. Anti-IFN antibody inhibited the migratory activity in response to not only IFN- $\gamma$ but also to the plasma from patients with Kawasaki disease. Rabbit AECA
\end{abstract}

(rAECA) also significantly stimulated the migration of tHUE01 cells. Plasma from patients treated with IVGG did not affect the migration of tHUE01 cells. Addition of $\gamma$-globulin significantly inhibited the migration of tHUE 01 cells induced by the cytokines or rAECA. These results suggest that cytokines and AECA are important in restructuring and destroying vessel walls in Kawasaki disease by enhancing the migration of endothelial cells, and that IVGG may be therapeutically effective for this disease by suppressing this endothelial cell migration. (Pediatr Res 38: 501-505, 1995)

\section{Abbreviations}

AECA, anti-endothelial cell antibody

RAECA, rabbit AECA

IVGG, intravenous administration of high doses $\gamma$-globulin

IFN, interferon

TNF, tumor necrosis factor
Kawasaki disease is always accompanied by systemic vasculitis including coronary arteritis, which often causes coronary aneurysms frequently followed by coronary stenosis. The first choice of therapy for Kawasaki disease is IVGG (1-4). Patients with Kawasaki disease show several immunoregulatory abnormalities: e.g. increases in levels of cytotoxic cytokines such as TNF and IFN, and autoantibodies including AECA in their sera (5-9). The therapeutic effect of IVGG has been reported to be mediated by normalizing these immunoregulatory abnormalities $(1,7)$. However, we do not yet know the mechanism responsible for the destruction and reconstruction of vessel walls, inducing aneurysm in Kawasaki disease. As the first step for determining the mechanism of aneurysm production, we must clarify the changes in biologic behavior of

Received October 21, 1994; accepted May 19, 1995.

Correspondence and reprint requests: Koichi Sakata, M.D., Children's Research Hospital, Kyoto Prefectural University of Medicine, 465 Kajii-cho, Kawaramachi-Hirokoji, Kamigyo-ku, Kyoto 602, Japan. endothelial cells caused by the immunoregulatory abnormalities in Kawasaki disease. Therefore, we examined the effects of cytokines, AECA, and $\gamma$-globulin on the migration of endothelial cells, which is a fundamental process in both the repair and exacerbation of vascular damage (10-12).

\section{METHODS}

Subjects. Twenty-eight children with Kawasaki disease were entered in the study as the patient group: 16 boys and 12 girls, 3 mo to $6 \mathrm{y}$ of age (mean, $3 \mathrm{y}, 7 \mathrm{mo}$ ). Ten healthy children admitted for the catheterization for noncyanotic congenital heart disease without heart failure or for arrhythmic disease were regarded as healthy controls: 6 boys and 4 girls, 3 mo to $5 \mathrm{y}$ of age (mean, $3 \mathrm{y}$ ). Twelve children with febrile disease ( 2 with bronchitis, 4 with pneumonia, 2 with urinary tract infection, 2 with enterocolitis, and 2 with meningitis) were considered as febrile controls: 6 boys and 6 girls, $1-6$ y of age (mean, $3 \mathrm{y}, 2 \mathrm{mo}$ ). 
Plasma. The plasma separated from whole heparinized blood of subjects was stored at $-80^{\circ} \mathrm{C}$ until use.

Culture of endothelial cell line. The human umbilical vein cell line (tHUE01) was grown in Dulbecco's modified Eagle's medium supplemented with $10 \%$ fetal bovine serum (GeminiBioproducts, Inc., Calabasas, CA), $2 \mathrm{mM}$ L-glutamine, and 60 $\mathrm{mg} / \mathrm{mL}$ kanamycin, in a $5 \% \mathrm{CO}_{2}$ atmosphere at $37^{\circ} \mathrm{C}$. When the cells reached confluence, they were subcultured by treatment with trypsin/EDTA (Mochida Pharmaceutical Co. Ltd., Osaka, Japan), and suspended at $1 \times 10^{5} / \mathrm{mL}$ in serum-free Dulbecco's modified Eagle's medium.

Determination of cytokines and AECA in plasma from patients. To obtain preliminary data, we examined plasma IFN activity by the dye uptake method, and TNF- $\alpha$, IL- $1 \beta$, and IL- 6 by the ELISA method as described previously (13). The presence of AECA was also confirmed by the cellular-based modified ELISA method as described previously (9).

Preparation of cytokines and $\gamma$-globulin. Recombinant human IFN- $\gamma$ (Kyowa-Hakko Kogyo, Co., Ltd., Tokyo, Japan), TNF- $\alpha$, IL- $1 \beta$, and IL-6 (R\&D System Inc., Minneapolis, MN) were prepared for the study. Five different $\gamma$-globulin preparations composed of intact $\mathrm{Fc}$ fragment were obtained from sources as follows: two lots from Teijin Inc., one from Bayer Yakuhin, Co., Ltd., and two from Midori-Juji Inc., Osaka, Japan.

Preparation of rabbit anti-tHUE01 cell-specific antibody ( $\boldsymbol{F A E C A}$. An adult Japanese white rabbit immunized with $1 \times$ $10^{6}$ tHUE01 cells/mL of PBS twice at an interval of 2 wk. Rabbit serum was separated from the whole blood at 2 wk after the last immunization. Anti-tHUE01 cell-specific antibody in the sera (rAECA preparation) was detected by immunohistologic staining using a Vectastain $\mathrm{ABC}$ kit (Vector Labs., Burlingame, CA). Rabbit serum was stored at $-80^{\circ} \mathrm{C}$ until use.

Migration assay. Migration assays were performed using a modified Boyden chamber method (Chemotaxicell with 8- $\mu \mathrm{m}$ pore size polycarbonate filter; Kurabo, Co., Ltd., Osaka, Japan). Diluted samples (1\% plasma, $1 \%$ albumin, cytokines, or rAECA preparation) were placed in the lower chamber, and $200 \mu \mathrm{L}$ of tHUE01 cell suspension containing $2 \times 10^{4}$ cells were then placed in the upper chamber. The chambers were incubated in a humidified atmosphere of $5 \% \mathrm{CO}_{2}$ in air for 24 $h$ at $37^{\circ} \mathrm{C}$. This time was sufficient to allow good levels of cell migration. Subsequently, the filter was removed from the Chemotaxicell chamber. Migrated cells were then fixed with $70 \%$ ethanol, stained with hematoxylin, and counted under a light microscope. All assays were performed in triplicate, and results were expressed as the mean number of migrated cells in all fields examined. Migration index was calculated by the following formula: migration index $=$ mean number of migrated cells treated with plasma solution/mean number of those treated with albumin.

Neutralizing assay by anti-IFN- $\gamma$ antibody on tHUE01 cell migration. One thousand neurtalizing units (NU) $\mathrm{NU} / \mathrm{mL}$ of anti-IFN- $\gamma$ antibody (Hayashibara Bio-Chem., Lab., Inc., Okayama, Japan) were preincubated with each test sample, diluted plasma solution, or $100 \mathrm{IU} / \mathrm{mL}$ of IFN- $\gamma$ solution, for 1 h. Samples were then used in the migration assay.

Statistical analysis. Data were analyzed by a $t$ test. If the $p$ value was $<0.05$, the difference was considered to be significant.

\section{RESULTS}

The IFN, TNF- $\alpha$, IL- $1 \beta$, and IL- 6 levels in plasma from patients in acute phases of the disease were significantly higher than those in plasma taken in the convalescent phase or from healthy children (Table 1). In all of the patients from whom serial samples were available, each cytokine level was higher during the acute phase than that during the post-IVGG phase or later phase ( $p<0.001$, paired $t$ test). The presence of IgM or IgG classes of AECA was also confirmed in 10 patients during the acute to subacute phase.

Endothelial cell migration. The plasma of patients in the acute phase significantly enhanced the migration of tHUE01 cells, compared with those of healthy and febrile controls (Fig. 1). All patient's serial samples showed a decrease in migration index during the post-IVGG to convalescent phases (Fig. 1).

The influence of cytokines and AECA. Some cytokines are known to be potent migration-stimulating factors for a variety cells including epidermal cells and leukocytes. To determine whether tHUE01 cell migration was caused by stimulators in the plasma from patients, we examined the effects of cytokines

Table 1. The levels of cytokines in plasma from patients with Kawasaki disease

\begin{tabular}{|c|c|c|c|c|c|c|}
\hline \multirow[b]{3}{*}{ Cytokine } & \multicolumn{2}{|c|}{ Control } & \multicolumn{4}{|c|}{ Patient phase } \\
\hline & Healthy & Febrile & I & II & III & IV \\
\hline & $n=10$ & $n=12$ & $n=28$ & $n=18$ & $n=24$ & $n=26$ \\
\hline IFN (IU/mL) & $<4$ & $7.0 \pm 6.3$ & $73.1 \pm 68.6^{* *} \|$ & $17.6 \pm 17.2$ & $13.9 \pm 17.2$ & $12.2 \pm 12.9 \S$ \\
\hline $\mathrm{TNF}_{-\alpha}(\mathrm{pg} / \mathrm{mL})$ & $<20$ & $<20$ & $117.9 \pm 164.8 * \dagger$ & $118.1 \pm 186.3^{*} \dagger$ & $<20$ & $<20 \S$ \\
\hline IL-1 $\beta(\mathrm{pg} / \mathrm{mL})$ & $<100$ & $<100$ & $116.2 \pm 36.1^{* \dagger}$ & $<100$ & $<100$ & $<100 \S$ \\
\hline IL-6 (pg/mL) & $<4$ & $59.7 \pm 3.5$ & $243.8 \pm 239.2 * \dagger$ & $22.7 \pm 44.6^{*} \dagger$ & $4.3 \pm 1.1$ & $<4 \S$ \\
\hline
\end{tabular}

Values are mean \pm SD. Phase I (acute phase), within $7 \mathrm{~d}$ of onset of the disease; phase II (post-IVGG), immediately after IVGG, within $14 \mathrm{~d}$ of onset; phase III (subacute), within 2 mo of onset; phase IV (convalescent), over 4 mo after onset of the disease. Cut of values: IFN, 4 IU/mL; TNF- $\alpha, 20 \mathrm{pg} / \mathrm{mL} ; \mathrm{IL}-1 \beta, 100$ $\mathrm{pg} / \mathrm{mL} ; \mathrm{IL}-6,4 \mathrm{pg} / \mathrm{mL}$

$* p<0.05$.

${ }^{* *} p<0.01 v s$ healthy control.

$\dagger p<0.05$.

$\| p<0.01 v s$ febrile control.

$\S p<0.001$ vs phase I. 


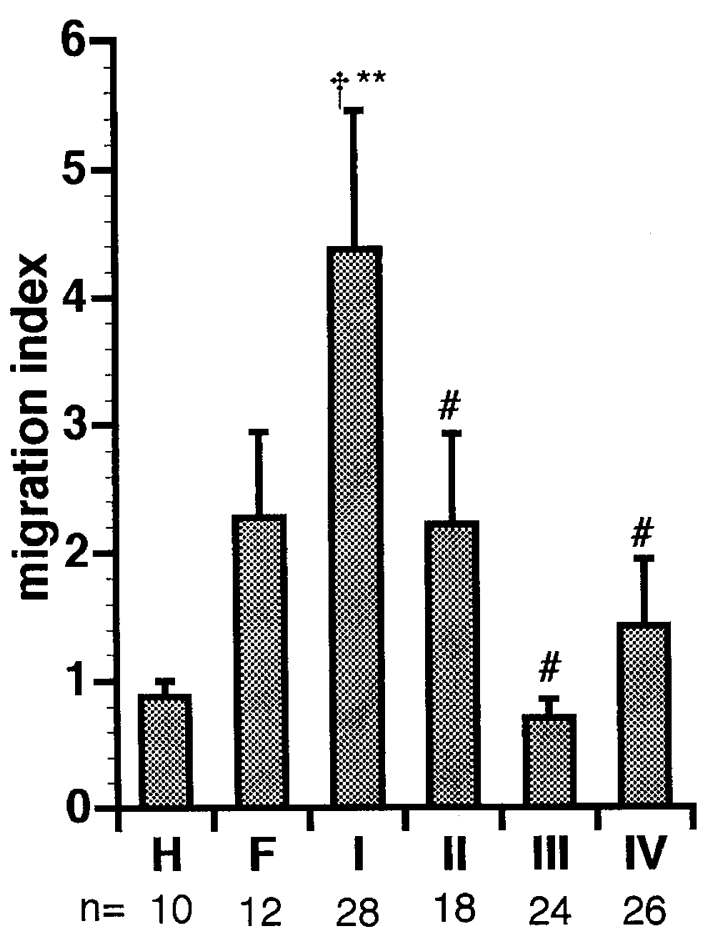

Figure 1. Migration of tHUE01 cells induced by plasma samples. $H$, healthy control; $F$, febrile control; phase $I$ (acute phase), within $7 \mathrm{~d}$ of onset of the disease; II (post-IVGG phase), immediately after IVGG, within $14 \mathrm{~d}$ of onset; $I I I$ (subacute phase), within 2 mo of onset; IV (convalescent phase), over 4 mo after onset of the disease. The migration assay was performed by a modified Boyden chamber method. The migrated cells were counted in all fields of the membrane after incubation for $24 \mathrm{~h}$. The migration index was calculated by the formula: (mean number of migrated cells treated with plasma solution)/(mean number of those treated with albumin). Values represent mean \pm SEM. $\dagger p<$ 0.005 vs $\mathrm{H},{ }^{* *} p<0.01$ vs $F, \# p<0.005$ vs $\mathrm{I}$.

and AECA, which were elevated in the patients' plasma, on cell migration.

Recombinant IL- $1 \beta$ or IL- 6 significantly enhanced the migration of tHUE01 cells in an almost dose-dependent manner (Fig. 2). Migration-stimulatory activity of IFN- $\gamma$ reached its peak at $100 \mathrm{IU} / \mathrm{mL}$. Anti-IFN- $\gamma$ antibody neutralized this stimulatory effect of IFN- $\gamma$ on migration, although anti-IFN- $\gamma$ antibody itself had no influence on the migration. The neutralizing effect was also observed by preincubation of the plasma from eight patients which showed marked enhancement of migration with $1000 \mathrm{NU} / \mathrm{mL}$ of anti-IFN- $\gamma$ antibody at $37^{\circ} \mathrm{C}$ for $1 \mathrm{~h}$ (Fig. 3).

Highly diluted rAECA preparations, even at $1 \times 10^{-4}$ dilution, significantly enhanced the migration of tHUE01 cells (Fig. 4). The migratory effect of rAECA preparations, at $1 \times$ $10^{-4}$ dilution, was not decreased by heat treatment at $56^{\circ} \mathrm{C}$ for $30 \mathrm{~min}$. However, this migratory activity was decreased by absorbing rAECA to tHUE01 cells (Fig. 4).

Effects of $\gamma$-globulin on the migration of tHUE01 cells. Each $\gamma$-globulin preparation significantly suppressed the migration of tHUE01 cells in a dose-dependent manner. This suppressive effect was observed even in the presence of 100 $\mathrm{IU} / \mathrm{mL}$ IFN- $\gamma$ or a $1 \times 10^{-4}$ diluted rAECA preparation (Fig. 5).

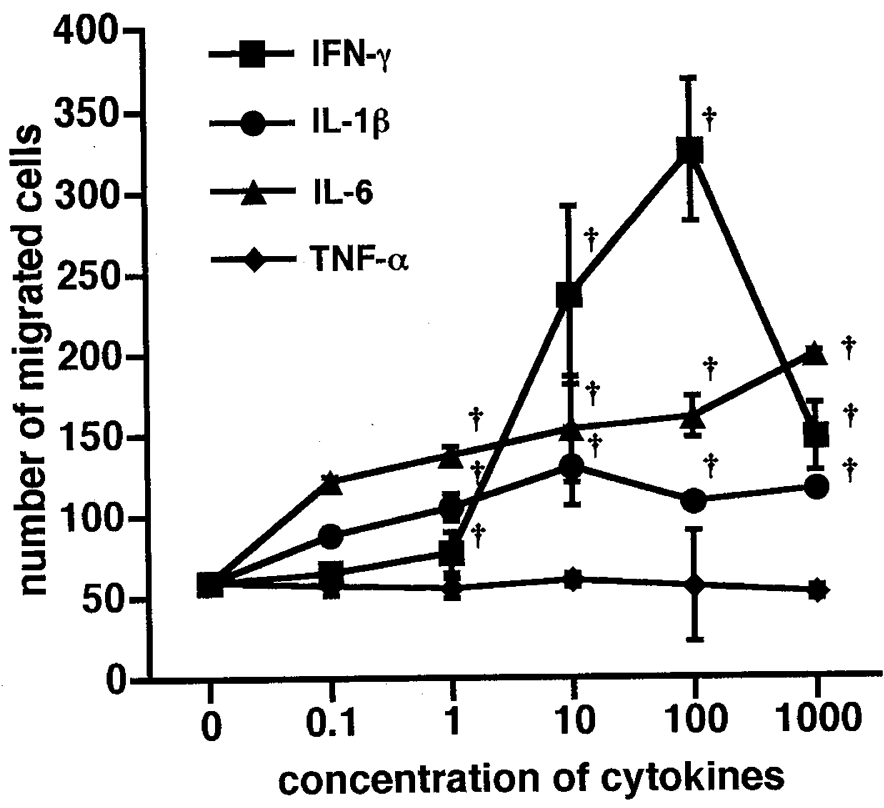

(IFN- $:$ IU $/ \mathrm{mL}$, TNF $-\alpha, \mathrm{IL}-1 \beta, \mathrm{IL}-6: \mathrm{pg} / \mathrm{mL}$ )

Figure 2. Effects of cytokines on the migration of tHUE01 cells. The migration assay was performed as described in Fig. 1. Values present mean $\pm \mathrm{SD}$. $\dagger p<0.005$ vs $0 \mathrm{IU} / \mathrm{mL}$ (or $\mathrm{pg} / \mathrm{mL}$ ) of cytokines.

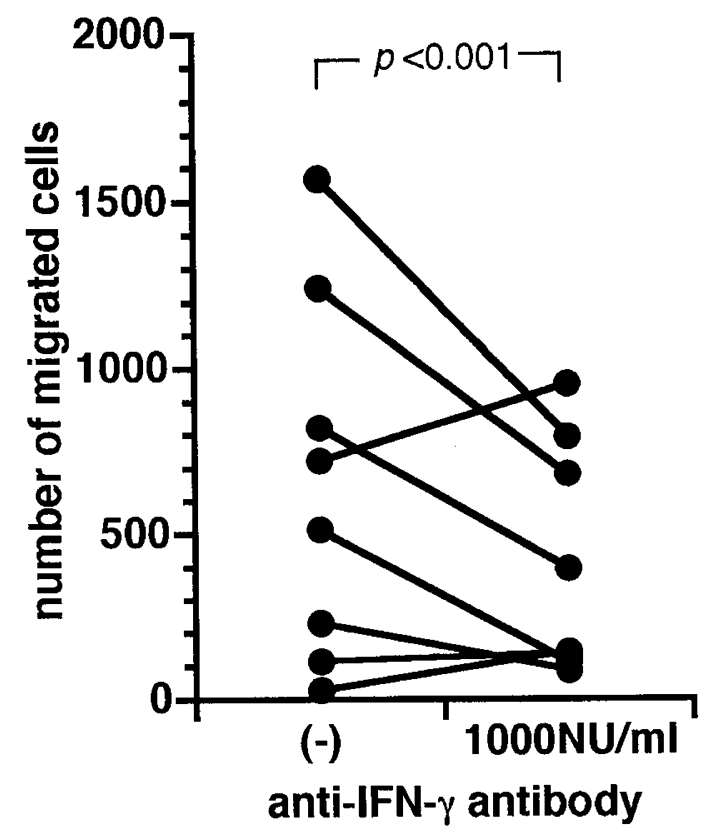

Figure 3. Neutralization of plasma-induced migratory activity by anti-IFN- $\gamma$ antibody. Anti-IFN- $\gamma$ antibody was added at $1000 \mathrm{NU} / \mathrm{mL}$ to plasma samples from the eight patients which showed high levels of migratory activity of tHUE01 cells. The migration assay was performed as described in Fig. 1.

\section{DISCUSSION}

Migration and proliferation of endothelial cells are the most important processes in both the repair and exacerbation of vascular damage. In other words, these behaviors of endothelial cells are the key factors in the destruction and reconstruction of vessel walls $(10-12)$.

It is, therefore, indispensable to determine both the proliferation and migration of endothelial cells in Kawasaki disease 


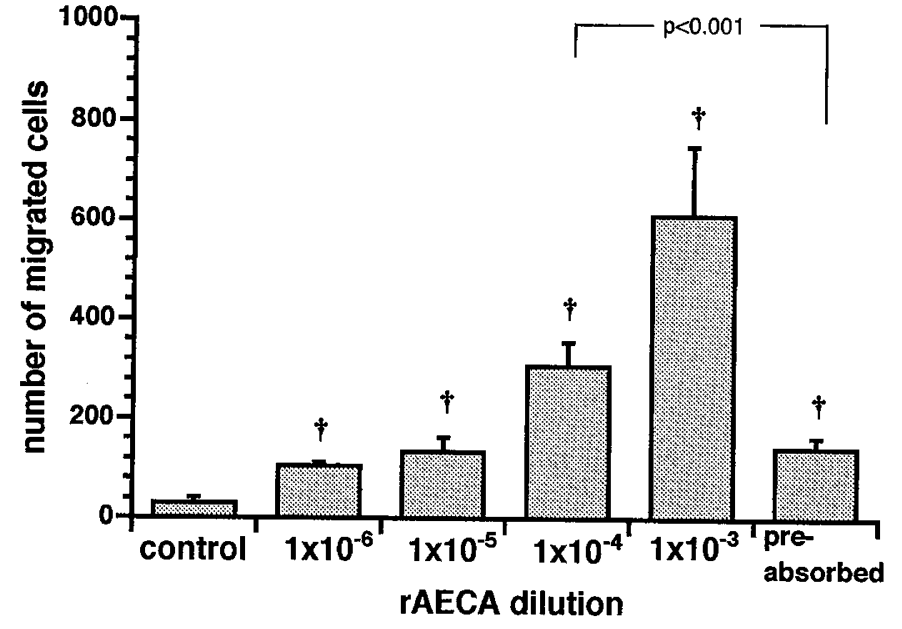

Figure 4. Migration of tHUE01 cells stimulated by rAECA. rAECA was used at dilutions varying from $1 \times 10^{-6}$ to $1 \times 10^{-3}$. The concentration of specific antibody in rAECA, at $1 \times 10^{-4}$ dilution, was decreased by preincubation with tHUE01 cells at $37^{\circ} \mathrm{C}$ for $1 \mathrm{~h}$ (preabsorbed sample). The migration assay was performed as described in Fig. 1. Values present mean $\pm \mathrm{SD} . \dagger p<0.005 v s$ control.

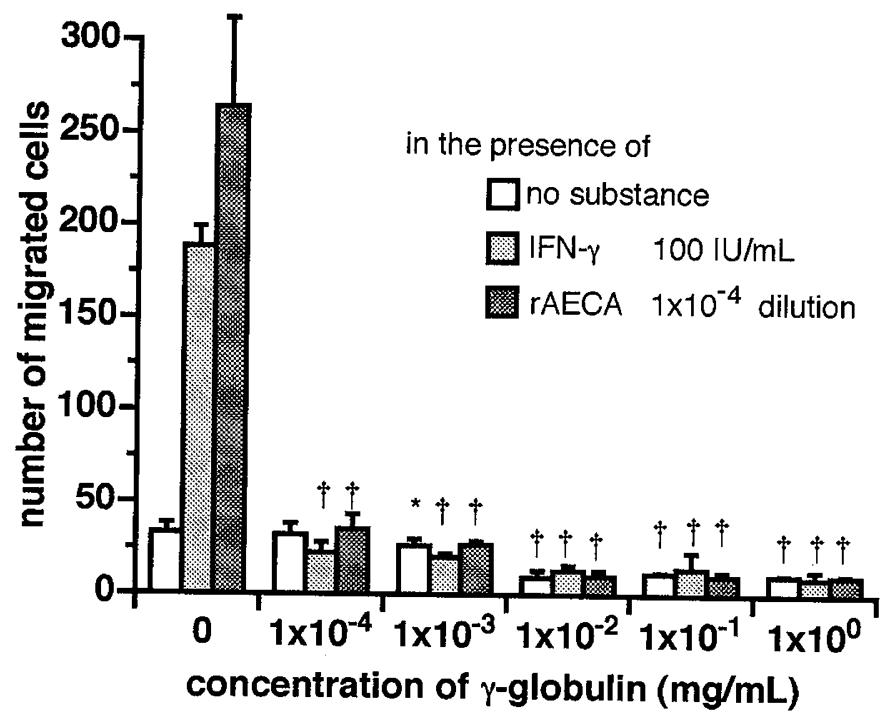

Figure 5. Effects of $\gamma$-globulin on the migration of tHUE01 cells. $\gamma$-Globulin preparations were added to the experimental samples without a chemotactic factor, or with $100 \mathrm{IU} / \mathrm{mL}$ of IFN- $\gamma$ or $1 \times 10^{-4}$ diluted rAECA. The migration assay was performed as described in Fig. 1. Values present mean \pm SD. ${ }^{*} p<0.05, \dagger p<0.005$ vs $0 \mathrm{mg} / \mathrm{mL}$ of $\gamma$-globulin.

for elucidation of the mechanism producing coronary aneurysm in this disease.

Sera from the majority of patients with Kawasaki disease during the acute phase have been shown to significantly enhance endothelial cell proliferation, although the exact nature of the stimulator in the sera was not clearly identified (14). On the other hand, there have been no previous reports concerning the migration of endothelial cells in Kawasaki disease.

Chemotaxicell, a modified Boyden chamber unit, allowed us to carry out experiments using many samples from patients and to obtain reproducible results.

In the present study, the plasma from patients significantly enhanced the migration of endothelial cells in the acute phase, compared with plasma from controls. Patients' serum samples obtained during the post-IVGG to convalescent phase did not enhance the migration of tHUE01 cells.

These results indicate that a certain factor included in the plasma at the acute phase of the disease enhances the migration of endothelial cells, and that $\gamma$-globulin supplied by IVGG suppresses migration by direct action on the endothelial cells or by inhibition of chemotactic factors.

The elevation of some cytokines and AECA in the plasma from the patients was observed in the present study, and these results are in agreement with previous reports $(6,7,9)$. Some cytokines are known to be migration-stimulating factors for various cells $(10,12)$. It is, therefore, highly possible that cytokines in the plasma from patients act as stimulators of endothelial cell migration. In fact, IFN- $\gamma$, IL- $1 \beta$, and IL-6 showed enhancement of migration of tHUE01 cells. Furthermore, anti-IFN- $\gamma$ antibody markedly inhibited the migrationenhancing activity of IFN- $\gamma$ on tHUE01 cells. Preincubation of anti-IFN- $\gamma$ antibody with the patients' plasma samples also showed a similar neutralizing effect.

It is concluded from these results that cytokines including IFN- $\gamma$ in the plasma during acute to subacute phases of Kawasaki disease are stimulators of the migration of endothelial cells.

We examined whether AECA in Kawasaki disease is also a stimulator of endothelial cell migration. A rAECA preparation was used for chemotactic assay, as it is technically difficult to isolate AECA from the plasma of patients. The rAECA preparation used here also showed marked stimulation of endothelial cell migration.

However, we cannot exclude the possibility that substances other than rAECA affect the migration of tHUE01 cells. Heating the rAECA preparation at $56^{\circ} \mathrm{C}$ for $30 \mathrm{~min}$ did not suppress its migration-enhancing effect, indicating that the activation of complement components is not involved in the enhancement of migration. However, the stimulatory activity of the rAECA preparation was markedly reduced by preincubation with tHUE01 cells. From these results, rAECA itself appeared to stimulate the migration of tHUE01 cells.

IVGG is one of the most effective therapies for Kawasaki disease, preventing formation of coronary aneurysm in patients $(1,2)$. Therefore, we examined the effects of $\gamma$-globulin administration on the migration of endothelial cells. $\gamma$-Globulin showed a suppressive effect on the migration of tHUE01 cells, and this effect was dominant in the presence of cytokines or a rAECA preparation. These results suggest that the suppression of endothelial cell migration may be involved in the prevention of aneurysm formation by IVGG.

It is known that the migration of endothelial cells constituting vessel walls plays an important role in injury or repairment of vessels, by destroying and restructuring the basement membrane and/or the extracellular matrix $(11,15-18)$. Therefore, it is concluded that the observed enhancement of migration of endothelial cells by the cytokines and/or AECA is closely related to the formation of vascular lesions in Kawasaki disease. The therapeutic effect of IVGG may, thus, be partly due to suppression of the excessive migration of endothelial cells. 


\section{REFERENCES}

1. Harada K 1991 Intravenous $\gamma$-globulin treatment in Kawasaki disease. Acta Paediatr Jpn 33:805-810

2. Furusho K, Kamiya T, Nakano H, Kiyosawa N, Shinomiya K, Hayashidera T, Tamura T, Hirose O, Manabe Y, Yokoyama T 1991 Intravenous $\gamma$-globulin for Kawasaki disease. Acta Paediatr Jpn 33:799-804

3. Leung DY 1989 Clinical and immunologic aspects of Kawasaki disease. Immunodefic Rev 1:261-271

4. Newburger JW, Takahashi M, Beiser AS, Burns JC, Bastian J, Chung KJ, Colan SD, Duffy CE, Fulton DR, Glode MP 1991 A single intravenous infusion of gamma globulin as compared with four infusions in the treatment of acute Kawasaki syndrome. N Engl J Med 324:1633-1639

5. Lin CY, Lin CC, Hwang B, Chiang BN 1991 The changes of interleukin-2, tumour necrotic factor and $\gamma$-interferon production among patients with Kawasaki disease. Eur J Pediatr 150:179-182

6. Matsubara T, Furukawa S, Yabuta K 1990 Serum levels of tumor necrosis factor, interleukin 2 receptor, and interferon- $\gamma$ in Kawasaki disease involved coronary-artery lesions. Clin Immunol Immunopathol 56:29-36

7. Leung DY 1991 The potential role of cytokine-mediated vascular endothelial activation in the pathogenesis of Kawasaki disease. Acta Paediatr Jpn 33:739-744

8. Abe J, Kotzin BL, Meissner C, Melish ME, Takahashi M, Fulton D, Romagne F, Malissen B, Leung DY 1993 Characterization of T cell repertoire changes in acute Kawasaki disease. J Exp Med 177:791-796

9. Tizard EJ, Baguley E, Hughes GR, Dillon MJ 1991 Antiendothelial cell antibodies detected by a cellular based ELISA in Kawasaki disease. Arch Dis Child 66:189-192
10. Rosen EM, Grant D, Kleinman H, Jaken S, Donovan MA, Setter E, Luckett PM, Carley W, Bhargava M, Goldberg ID 1991 Scatter factor stimulates migration of vascular endothelium and capillary-like tube formation. Experientia Suppl 59:76-88

11. Apodaca G, Rutka JT, Bouhana K, Berens ME, Giblin JR, Rosenblum ML, McKerrow JH, Banda MJ 1990 Expression of metalloproteinases and metalloproteinase inhibitors by fetal astrocytes and glioma cells. Cancer Res 50:2322-2329

12. Rosen EM, Liu D, Setter E, Bhargava M, Goldberg ID 1991 Interleukin-6 stimulates motility of vascular endothelium. Experientia Suppl 59:194-205

13. Kita M, Ohmoto Y, Hira Y, Yamaguchi N, Imanishi J 1992 Induction of cytokines in human peripheral blood mononuclear cells by mycoplasmas. Microbiol Immunol 36:507-516

14. Hashimoto Y, Yoshinoya S, Aikawa T, Mitamura T, Miyoshi Y, Muranaka M, Miyamoto T, Yanase Y, Kawasaki T 1986 Enhanced endothelial cell proliferation in acute Kawasaki disease (muco-cutaneous lymph node syndrome). Pediatr Res 20:943-946

15. Montesano R, Vassalli JD, Baird A, Guillemin R, Orci L 1986 Basic fibroblast growth factor induces angiogenesis in vitro. Proc Natl Acad Sci USA 83:7297-7301

16. Reilly W, McAuslan BR 1988 Matrix control of tumor angiogenesis. Adv Exp Med Biol 242:221-227

17. Roberts JM, Forrester JV 1990 Factors affecting the migration and growth of endothelial cells from microvessels of bovine retina. Exp Eye Res 50:165-172

18. Mawatari M, Okamura K, Matsuda T, Hamanaka R, Mizoguchi H, Higashio K, Kohno K Kuwano M 1991 Tumor necrosis factor and epidermal growth factor modulate migration of human microvascular endothelial cells and production of tissue-type plasminogen activator and its inhibitor. Exp Cell Res 192:574-580 